\title{
Comparison of the single breath with the intrabreath method for the measurement of the carbon monoxide transfer factor in subjects with and without airways obstruction
}

\author{
Dora Kiss, Wolfgang Popp, Christian Wagner, Liselotte Havelec, Kaspar Sertl
}

\begin{abstract}
Background - Measurement of the carbon monoxide transfer factor (TLCO) has traditionally been performed using the single breath method but recently the intrabreath method has been developed. The aim of this study was to compare the two methods in the clinical evaluation of patients with obstructive and non-obstructive pulmonary disorders.
\end{abstract}

Methods-Measurements of TLCO with the intrabreath method were carried out on a study sample composed of 50 patients with non-obstructive disorders and 50 with airways obstruction $\left(\mathrm{FEV}_{1} / \mathrm{FVC}<70 \%\right)$ either before or after a single breath measurement of the TLCo had been performed. The method involves the continuous analysis of a single slow expirate using a computerised rapid multigas infrared analyser. TLCO, alveolar volume (VA), TLCo/VA, and inspired vital capacity (IVC) values were obtained for both groups by both methods. Results - When measured with the intrabreath method the group with airways obstruction showed lower TLCO and TLCO/ VA values than the non-obstructive group. VA was higher in both patient groups when measured with the intrabreath technique. The same test also showed higher TLCo values with the intrabreath method in the group with non-obstructive disorders and lower TLCO/VA values with the intrabreath method in those with airways obstruction. The corresponding parameters obtained by the two methods correlated closely, with no correlation between the magnitude of the differences with the magnitude of the readings. An index of gas mixing indicated a better distribution of the inspired air for the intrabreath method than for the single breath method. The VA values obtained with the intrabreath method showed a closer agreement to the actual total lung capacities measured by body plethysmography.

Conclusion - The intrabreath method of determining TLCo is comparable to the traditional single breath method. Meas- urement of alveolar volume by the intrabreath method approximates more closely to total lung capacity, even in subjects with airways obstruction.

(Thorax 1995;50:902-905)

Keywords: carbon monoxide transfer factor, intrabreath method, single breath method.

Since its introduction by Krogh in $1914^{1}$ the measurement of the carbon monoxide transfer factor of the lung (TLCO) has become part of pulmonary function testing. The established method is the TLCo single breath technique combined with the measurement of the alveolar volume (VA) from the single breath dilution of an inert tracer gas such as helium or methane. ${ }^{23}$ With this conventional technique a sample of the expired air is analysed after a period of breath holding at total lung capacity. Continuous gas analysis is now possible which reduces errors in gas analysis ${ }^{4-6}$ and permits a new approach to the measurement of TLCO; this method is called the intrabreath technique. ${ }^{78}$ With this method TLCo is measured by the rapid infrared analysis of methane and carbon monoxide during a single slow exhalation..$^{910}$

The intrabreath method is easy to perform, even in patients suffering from dyspnoea. This study was designed to compare the reliability, reproducibility, and accuracy of the single breath method with that of the intrabreath method in subjects with non-obstructive pulmonary disorders and those with airways obstruction.

\section{Methods}

STUDY POPULATION

The study population consisted of 100 consecutive patients in whom the TLCo was measured as part of their diagnostic evaluation. This population was divided into two groups each of 50 subjects: (1) those with a forced expiratory volume in one second/forced vital capacity $\left(\mathrm{FEV}_{1} / \mathrm{FVC}\right)$ value of $\geqslant 70 \%$ and both $\mathrm{FEV}_{1}$ and FVC within the normal range; and (2) a group with airways obstruction with a $\mathrm{FEV}_{1}$ /

\author{
Returned to authors \\ 29 October 1993 \\ Revised version received \\ 26 January 1994 \\ Accepted for publication \\ 17 May 1995
}


Table 1 Mean (SD) characteristics of the study population

\begin{tabular}{lll}
\hline & $\begin{array}{l}\text { Non-obstructive group } \\
(n=50)\end{array}$ & $\begin{array}{l}\text { Obstructive group } \\
(n=50)\end{array}$ \\
\hline M:F & $26: 24$ & $28: 22$ \\
Age (years) & $53 \cdot 0(23-80)$ & $58 \cdot 7(32-79)$ \\
Height (cm) & $171(152-193)$ & $172(160-187)$ \\
FVC (l) & $4 \cdot 00(1 \cdot 19)$ & $3 \cdot 76(0 \cdot 91)$ \\
FEV $_{1}(1)$ & $3 \cdot 14(0 \cdot 98)$ & $2 \cdot 38(0 \cdot 71)$ \\
FEV $_{1} /$ FVC (\%) & $77 \cdot 0(4 \cdot 63)$ & $60 \cdot 6(9 \cdot 10)$ \\
Range FEV $/$ /FVC (\%) & $70-90$ & $41-69$ \\
\hline
\end{tabular}

$\mathrm{FVC}=$ forced vital capacity; $\mathrm{FEV}_{1}=$ forced expiratory volume in one second.

FVC value of $<70 \%$. There were no patients with restrictive respiratory disorders in the study population. The patients with airways obstruction were all in a stable clinical condition; 41 presented with mild to moderate obstruction $\left(\mathrm{FEV}_{1}>60 \%\right.$ predicted) and nine suffered from a more severe chronic airways obstruction $\left(\mathrm{FEV}_{1}<60 \%\right.$ predicted). Details of the study population are given in table 1 .

\section{MEASUREMENTS}

All measurements were performed with an integrated computerised infrared analyser (Model 6200/SensorMedics, Bilthoven, Netherlands). Alveolar volume was obtained simultaneously by using methane as inert tracer gas. The analyser had a $0-90 \%$ response time of less than $300 \mathrm{~ms}$ (including transit delay time) and can analyse samples with volumes as small as $10 \mathrm{ml}$. The sample flow of the analyser is $500 \mathrm{ml} / \mathrm{min}$, and the dead space of the system is $80 \mathrm{ml}$ which is corrected mathematically in the calculation of VA. Volume and flow were measured by a heated wire device and calibrated daily using a 3 litre precision syringe. Before each test the analyser was zeroed against room air and calibrated using a test gas containing $3300 \mathrm{ppm}$ carbon monoxide, methane, and acetylene. The single breath TLCo tests were analysed using the visually adjusted method, where a washout volume adequate to clear the anatomical and apparatus dead space of carbon monoxide and methane and a sample volume of 0.751 (or 0.51 if the patient's vital capacity was $<2.01$ ) were set under visual control. This was accomplished by moving a cursor into the horizontal plateau of the graphical display of the gas concentrations on the monitor. Breath holding time was set according to the Meade-Jones method including two thirds of the time of inspiration and the time of expiration up to halfway through the period of sample collection. ${ }^{11}$ Reference values were taken from the Austrian recommendations for spirometry ${ }^{12}$ for $F E V_{1}$ and FVC, and from the transfer factor standards of the European Respiratory Society (ERS) for the calculation of TLCO predicted and TLCO/VA predicted. ${ }^{13}$

\section{TEST PROCEDURE}

Since there are no standards for the TLCO intrabreath test, the conditions of the measurements with both techniques were set in accordance with the recommendations of the
ERS for TLCo single breath tests. ${ }^{13}$ Thus, the tests were carried out in the afternoon with the subject in a relaxed seated posture maintained for 10 minutes. Between consecutive measurements there was an interval of at least four minutes. On the day of testing the subjects refrained from smoking and their last meal was at least two hours before the measurements started. All subjects underwent lung function tests where total lung capacity (TLC), residual volume (RV), FVC, FEV ${ }_{1}$ and $\mathrm{FEV}_{1} / \mathrm{FVC}$ were obtained. Before their first TLCO measurement they were carefully instructed about the procedure and fitted with noseclips.

The single breath manoeuvre consisted of an exhalation to RV followed by inhalation of a mixture of carbon monoxide and methane up to at least $90 \%$ of the patient's vital capacity. After breath holding at TLC for about 10 seconds the subject exhaled again into the system where the expired air underwent analysis.

The intrabreath manoeuvre was identical to the single breath technique up to the point of the breath holding, but the patient then immediately started a slow maximal exhalation instead of holding his breath. The patients were encouraged to exhale at a comfortable flow rate. To guarantee a fairly consistent and prolonged exhalation, which is essential for test accuracy, the patients exhaled through a flow restrictor between 335 and $665 \mathrm{l} / \mathrm{s}$ which was visually controlled. The ideal flow rate is $500 \mathrm{l} / \mathrm{s}$. The equations derived by Martonen and Wilson ${ }^{3}$ were applied to the calculations.

Two tests were considered reproducible if the results were within a $5 \%$ range. With each method two reproducible measurements were performed and TLCO, TLCo predicted, VA, TLCO/VA, TLCO/VA predicted, and inspiratory vital capacity (IVC) were obtained. Total lung capacity was calculated by adding dead space to the alveolar volumes obtained and the results compared with TLC values obtained by automated flow/volume body plethysmography in the course of the lung function tests. In addition, for both techniques and for both patient groups the index of gas mixing was calculated which reflects the distribution of the inspired test gas in the lung. ${ }^{14}$

\section{STATISTICAL ANALYSIS}

For a comparison of means between the nonobstructive and obstructive groups the two sample $t$ test was applied. The significance of mean differences between the two techniques was assessed by using the two sample $t$ test, and the Pearson coefficient of correlation between the comparable measurements with the two techniques was calculated. The Altman-Bland test was applied to analyse the significance of the correlation between the differences and average values of the single breath and intrabreath techniques. ${ }^{15}$ To investigate the significance of differences between the indices of gas mixing of the two methods the two sample Kolmogoroff-Smirnoff test was used. Statistical significance was accepted at the $5 \%$ level. ${ }^{1617}$ 


\section{Results}

The patients were instructed both before and during the tests, and most had no difficulty in achieving two reproducible measurements with both techniques. Fewer than $10 \%$ of the study sample needed a third test to meet these criteria. However, most of the subjects found the intrabreath method easier to perform.

The comparison of the means between the non-obstructive and the obstructive groups showed a significant difference with lower values in the obstructive group for TLCO $(\mathrm{p}<0.005)$ and TLCo/VA $(\mathrm{p}<0.001)$ when measured with the intrabreath method (table 2). The other tests, including those obtained with the single breath method, showed no significant difference between the non-obstructive and obstructive group.

In the intrabreath tests significantly higher TLCo $(p=0.005)$ and VA $(p<0.001)$ values were observed in the non-obstructive group, and significantly higher $\mathrm{VA}(\mathrm{p}<0.001)$ together with significantly lower TLCO/VA $(p<0.001)$ values were seen in the obstructive group than in the tests with the single breath technique. Significance was tested by applying the paired $t$ test for mean differences (table 3 ). The IVC values showed no significant differences between the two methods.

Table 2 Comparison of mean (SD) lung volumes between the two patient groups by two sample $t$ test

\begin{tabular}{|c|c|c|c|}
\hline & $\begin{array}{l}\text { Non-obstructive group } \\
(n=50)\end{array}$ & $\begin{array}{l}\text { Obstructive group } \\
(n=50)\end{array}$ & $p$ \\
\hline $\begin{array}{l}\text { TLco }(\mathrm{mmol} / \mathrm{kPa} / \mathrm{min}) \text { : } \\
\text { Intrabreath } \\
\text { Single breath } \\
\text { Single breath (\% pred) }\end{array}$ & $\begin{array}{l}7 \cdot 93(2 \cdot 62) \\
7 \cdot 44(2 \cdot 61) \\
79 \cdot 6(17 \cdot 6)\end{array}$ & $\begin{array}{l}6 \cdot 45(2 \cdot 45) \\
6 \cdot 69(2 \cdot 27) \\
74 \cdot 2(21 \cdot 6)\end{array}$ & $\begin{array}{l}<0 \cdot 005 \\
\text { NS } \\
\text { NS }\end{array}$ \\
\hline $\begin{array}{l}\text { TLco/VA: } \\
\text { Intrabreath } \\
\text { Single breath } \\
\text { Single breath }(\% \text { pred })\end{array}$ & $\begin{array}{l}1.40(0.28) \\
1.43(0.29) \\
92.8(19.4)\end{array}$ & $\begin{array}{l}1.14(0.37) \\
1.30(0.34) \\
87.6(20 \cdot 3)\end{array}$ & $\begin{array}{l}<0.001 \\
\text { NS } \\
\text { NS }\end{array}$ \\
\hline $\begin{array}{l}\text { VA (l): } \\
\text { Single breath } \\
\text { Intrabreath }\end{array}$ & $\begin{array}{l}5 \cdot 24(1 \cdot 52) \\
5 \cdot 68(1.58)\end{array}$ & $\begin{array}{l}5 \cdot 12(1 \cdot 14) \\
5 \cdot 65(1 \cdot 20)\end{array}$ & $\begin{array}{l}\text { NS } \\
\text { NS }\end{array}$ \\
\hline $\begin{array}{l}\text { IVC (l): } \\
\text { Single breath } \\
\text { Intrabreath }\end{array}$ & $\begin{array}{l}3.60(1.22) \\
3.57(1.30)\end{array}$ & $\begin{array}{l}3.44(0.88) \\
3.41(0.86)\end{array}$ & $\begin{array}{l}\text { NS } \\
\text { NS }\end{array}$ \\
\hline
\end{tabular}

$\mathrm{T}_{L C O}=$ lung carbon monoxide transfer factor; $\mathrm{VA}=$ alveolar volume; $\mathrm{IVC}=$ inspiratory vital capacity; NS = not significant

Table 3 Significance of mean differences between the single breath and intrabreath tests (paired t test)

\begin{tabular}{lccccc}
\hline & \multicolumn{2}{l}{ Non-obstructive group $(n=50)$} & & \multicolumn{2}{c}{ Obstructive group $(n=50)$} \\
\cline { 2 - 3 } \cline { 5 - 6 } & $t$ & $p$ & & & $p$ \\
\hline TLCo & -2.94 & 0.005 & & 1.35 & NS \\
TLCo (pred) & -3.27 & 0.002 & & 1.39 & NS \\
TLCO/VA & 1.18 & NS & & 6.27 & $<0.001$ \\
TLCO/VA (pred) & 1.16 & NS & & 6.34 & $<0.001$ \\
VA & -5.91 & $<0.001$ & & -7.79 & $<0.001$ \\
IVC & 0.43 & NS & & 1.14 & NS \\
\hline
\end{tabular}

TLCo $=$ lung carbon monoxide transfer factor; $V_{A}=$ alveolar volume; $I V C=$ inspiratory vital capacity; NS = not significant.

Table 4 Total lung capacity values (l) obtained by body plethysmography, by the single breath method, and the intrabreath method

\begin{tabular}{lll}
\multicolumn{1}{l}{ breath method, and the intrabreath method } \\
& $\begin{array}{l}\text { Non-obstructive group } \\
(n=50)\end{array}$ & $\begin{array}{l}\text { Obstructive group } \\
(n=50)\end{array}$ \\
\hline Body plethysmography & $6.04(1.43)$ & $6.50(1.46)$ \\
Single breath & $5.39(1.52) \dagger$ & $5.27(1.14)^{*}$ \\
Intrabreath & $5.83(1.58)$ & $5.80(1.20) \ddagger$ \\
\hline
\end{tabular}

${ }^{*} \mathrm{p}<0.001 ; \dagger \mathrm{p}<0.05 ; \ddagger \mathrm{p}<0.01$ compared with body plethysmography (paired $t$ test).
Regression analysis of comparable measurements performed with the two methods was evaluated for the two patient groups and showed a high correlation between the two methods over the whole range measured for both groups in all parameters $(\mathrm{p}<0.001)$.

To examine whether there was any systematic bias between the two methods and whether the magnitude of the differences was dependent on the magnitude of the readings the AltmanBland plot was applied to both patient groups and showed no statistical significance.

The distribution of the inspired gas for the two patient groups was evaluated by calculating the index of gas mixing (IGM $=\mathrm{VA} \times 100$ / TLC - anatomical dead space). The IGM is expressed as a percentage, where higher values indicate a better distribution of the inspired gas. ${ }^{14}$ As expected, a better distribution was observed in the non-obstructive group (single breath $88.4(8 \cdot 1) \%$; intrabreath $96.0(9 \cdot 2) \%)$ than in the obstructive group (single breath $81 \cdot 2(8 \cdot 1) \%$; intrabreath $89.9(9 \cdot 7) \%)$. For each group the mean values for the tests with the intrabreath technique were higher. The IGM values from both techniques were compared by applying the Kolmogoroff-Smirnoff test and significantly higher values, indicating a better gas distribution, were achieved with the intrabreath method $(\mathrm{p}<0.001)$.

Finally, the TLC values measured by body plethysmography were compared with those calculated by adding dead space volume to the alveolar volumes obtained by the two methods. Absolute values obtained with the intrabreath method showed a closer agreement with the TLC values measured by body plethysmography than did those obtained by the single breath method (table 4).

\section{Discussion}

This study compared the traditional single breath method with the newer intrabreath method for measuring TLCO in subjects with and without airways obstruction. In addition, the efficacy of both methods in determining the alveolar volume was investigated.

Our results confirm those previously reported by Wilson et $a l^{18}$ that the correlation of the two methods was highly significant over the whole range measured. Together with the results from the Altman-Bland test, this showed that the methods are comparable. However, in contrast to Wilson et al we observed significantly higher values of TLCO and VA by the intrabreath test in the subjects with nonobstructive disorders. The group with airways obstruction showed significantly higher VA and significantly lower TLCO/VA values by the intrabreath method than by the single breath method. These findings are consistent with the results of Jansons et al who compared the single breath method with the rebreathing method and concluded that the single breath measurement increasingly underestimates residual volume with increasing unequal ventilation. ${ }^{19}$

We suspected that the cause for these differences lay in the different determination of VA 
by the two methods. To examine the accuracy of both methods in assessing VA we compared the results with values for TLC obtained by body plethysmography and found a much closer agreement with the VA values from the intrabreath tests. Significantly higher values of VA were observed during the intrabreath tests, indicating a better distribution of the inspired gas. However, the portion of the expirate sampled early in exhalation during the single breath test presumably comes from less ventilated areas than those which are sampled later in the intrabreath test. ${ }^{7}$ This may also explain the higher VA values of the intrabreath method.

Thus, the intrabreath method was found to be reliable and accurate for determining TLco and merits standardisation. ${ }^{20}$ It is easier for the patient to perform than the traditional breath holding test. The derived alveolar volume approximates more closely to total lung capacity, even in patients with airways obstruction.

1 Krogh M. The diffusion of gases through the lungs of man. f Physiol (Lond) 1914;49:271-300

2 Ogilvie CM, Forster RE, Blakemore WS, Morton JW. A standardized breath holding technique for the clinical measurement of the diffusing capacity of the lung for carbon monoxide. 7 Clin Invest 1957;36:1-17.

3 Martonen TB, Wilson AF. Theoretical basis of single breath gas absorption tests. F Math Biol 1982;14:203-20.

4 Huang YT, Macintyre NR. Real-time gas analysis improves the measurement of single-breath diffusing capacity. $\mathrm{Am}$ the measurement of single-breath

5 Cotton DJ, Newth CJL, Portner PM, Nadel JA. Measurement of single breath diffusing capacity by continuous 6 Wapid CO analysis in man. F Appl Physiol 1979;46:1149-56. Wagner PD, Mazzone RW, West JB. Diffusing capacity and
anatomic dead space for carbon monoxide $\left(\mathrm{C}^{18} \mathrm{O}\right)$. $\mathcal{J} A p p l$ Physiol 1971;31:847-52.

7 MacIntyre NR, Nadel JA. Regional diffusing capacity in normal lungs during a slow exhalation. If Appl Physiol 1982;52:1487-92.

8 Newth CJL, Cotton DJ, Nadel JA. Pulmonary diffusing capacity measured at multiple intervals during a single slow exhalation in man. F Appl Physiol 1977;43:617-25.

9 Ramage JE, Coleman RE, Macintyre NR. Rest and exercise cardiac output and diffusing capacity assessed by a single slow exhation of methane, capetylene, and oxide. Chest 1987;92:44-50.

10 Elkayam U, Wilson AF, Morrison J, Meltzer P, Davis J, Klosterman P, et al. Non-invasive measurement of cardiac output by a single breath expiratory technique. Thorax 1984:39:107-13.

11 Jones RS, Meade F. A theoretical and experimental analysis of anomalies in the estimation of pulmonary diffusing capacity by the single breath method. $Q \mathcal{F}$ Exp Physiol 1961;46:131-43.

12 Forche G. Erste umfassende spirometrische Untersuchungen für neue uneingeschränkt anwendbare $\mathrm{Be}$ zugswerte. (Suppl) Wien Med Wochenschr 1986;99:1-36.

13 Cotes JE, Chinn DJ, Quanjer PH, Roca J, Yernault JC. Standardization of the measurement of transfer factor (diffusing capacity). Eur Respir f 1993;6(Suppl 16):41-52.

14 Miller WF, Scacci R, Gast LR. Laboratory evaluation of pulmonary function. Philadelphia: Lippincott, 1987.

15 Altman DG, Bland JM. Measurement in medicine: the analysis of method comparison studies. The Statistician 1983;32:307-17.

16 BPMD Statistical Software. Cork Technology Park, Model Farm Road, Cork, Ireland, 1990.

17 Sachs L. Angewandte Statistik. 7th edn. Berlin: Springer, 1993.

18 Wilson AF, Hearne J, Brenner M, Alfonso R. Measurement of transfer factor during constant exhalation. Thorax 1994; 49:1121-6.

19 Jansons H, Fokkens JK, van der Tweel I, Kreukniet J. Rebreathing TLCO versus single breath TLCO at different degrees of unequal ventilation. Respiration 1994;61:32-6.

20 American Thoracic Society. Single-breath carbon monoxide diffusing capacity (transfer factor). Am Rev Respir Dis diffusing capacity (tran 